\title{
Bullying Behavior and Psychosocial Health - A Cross-sectional Study among School Students of Pyuthan Municipality
}

\author{
Durga Khadka Mishra, ${ }^{1}$ Tulsi Ram Thapa, ${ }^{1}$ Sujan Babu Marahatta, ${ }^{1}$ Anita Mahotra ${ }^{1}$ \\ ${ }^{1}$ Manmohan Memorial Institute of Health Sciences, Soalteemode, Kathmandu, Nepal.
}

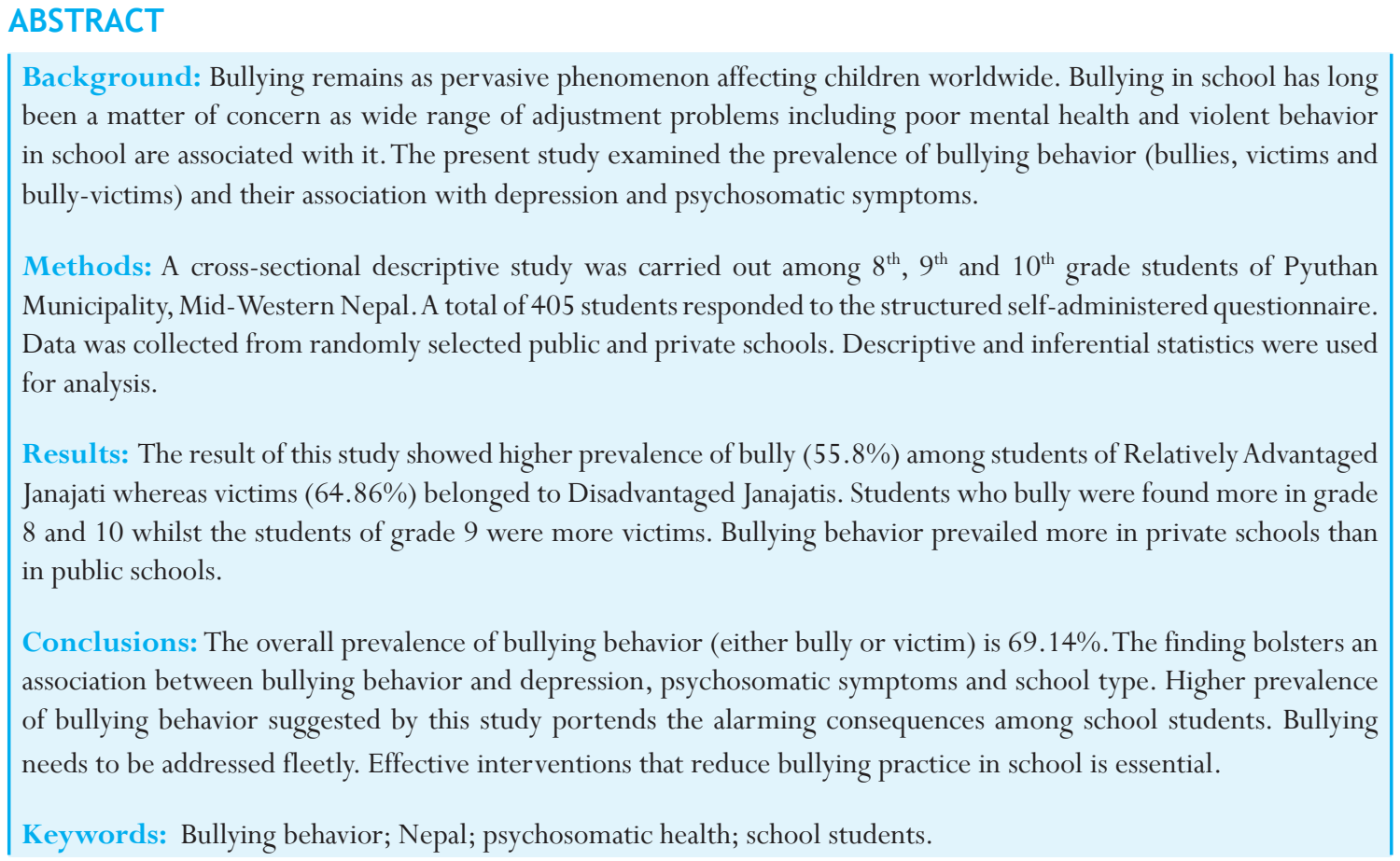

\section{INTRODUCTION}

Bullying, a worldwide phenomenon, mostly occurs among school children resulting to poor health. ${ }^{1-4}$ Bullying has been defined as the intentional unprovoked abuse of power by one or more children to inflict pain or cause distress to another child on repeated occasion with negative actions either physical contact, verbal assault, nonverbal gestures and intentional exclusion characterized by imbalance of power. ${ }^{2,3,5}$

Bully is the initiator of the bullying behavior whereas the victim is the target of bully. Bully-victim is the one who is being bullied by others and is started taking part in bullying others.

Bullying is often followed by short-term and long-term undesirable psychosocial consequences. ${ }^{6,7}$ Both the victims and perpetrators of bullying tend to have many physical and psychological symptoms, such as depressive symptomatology, sleeping difficulty, severe suicidal ideation, psychiatric and psychosomatic symptoms and may continue to adulthood. , 7-11 $^{-1}$

Qualitative study conducted in Nepal explored bullying as prominent issue in Nepal. ${ }^{12}$ However, quantitative study on bullying in Nepal has not been conducted till date. This study is therefore a small attempt to put the trigging stone into the still pond of school bullying research in Nepal.

\section{METHODS}

This was descriptive quantitative study conducted in five schools of Pyuthan municipality including both public and private. Students of grade 8th, 9th and 10th were selected using proportionate sampling. Study period was from April to May, 2016. Ethical approval

Correspondence: Ms Durga Khadka Mishra, Manmohan Memorial Institute of Health Sciences, Soalteemode, Kathmandu, Nepal. Email: durgamk07@gmail.com, Phone: +9779851022635. 
was obtained from Institutional Review Committee of Manmohan Memorial Institute of Health Sciences (MMIHS). Approval was obtained from District Education Office (DEO) Pyuthan. Formal permission was obtained from concerned authority. Written informed consent was obtained from each respondent with detail explanation of the purpose of the study to ensure their right to information. Confidentiality of respondent was maintained with an exemption to participate in the study or refuse to answer the question which they felt awkward with. Approval was obtained from parents of each respondent.

Simple random sampling was done to select the respondents. Sample size was calculated using the sampling formula.

This study used the self-administered structured questionnaire to collect the information. Standard questionnaire - "Olweus Bullying Questionnaire" was used to assess the information on bullying behavior and "A compendium Assessment Tools" developed by Centre for Disease Control (CDC) was used for measuring bullying victimization, perpetration and bystander experience. Assessment of Depression was done using PHQ-9 (Patient Health Questionnaire-9) developed by Kurt Kroenke and Rober L.Spitzer. Psychosomatic symptoms were assessed adopting SSS-8 scale (Somatic Symptoms Scale-8). A response of more than once or twice in each question was attributes to categorize the bully, victim and bullyvictim. Bully is the students who answered '2-3 times a month' for at least one question of bully-only scale. Victim is the students who answered ' $2-3$ times a month' for at least one question of victim-only scale. Bullyvictim is the students who answered ' $2-3$ times a month' for at least one question of each bully-only scale and victim-only scale.

Regarding the validity of the tool assessment tools were developed in close assistant of expertise. The study tools were pretested among 40 students in selected school of Pyuthan Municipality before conducting the actual study. Flaws encountered following pretest was corrected and modified prior to the actual study. To maintain the reliability, researcher themselves from the study team were involved in data collection.

Prior for the analysis, collected data were checked and data cleaning was done. Data entry and analysis was executed using SPSS version 20.0 (SPSS Inc.). Mean, Median age, Standard deviation was expressed using descriptive analysis. Association was expressed using inferential statistics - chi-square test. P-value less than 0.05 were considered as significant.

\section{RESULTS}

Mean age of the respondents participated in the study was 14.39 years. Median age was 14.0 years. Age range varied between 12 - 20 years. Mean age for the Bully, Victim and Bully-Victim was 14.50 years, 14.49 years and 14.53 years respectively. Participation of girls $(51.60 \%)$ in the study was higher as compared to boys (48.40\%). Upper caste group (54.81\%) represented the majority of participants followed by Disadvantaged Janajati (18.27\%) with least participants from religious minorities $(0.49 \%)$.

Study reported the augmented bullying behavior with increasing age group. Bullying behavior was exhibited more by boys than girls. Boys involved in bullying others (62.25\%) commensurate the boys being bullied by others $(62.76 \%)$. Relatively fewer girls were perpetrator and bully-victim as compared to the proportion of victimization. Prevalence of bully (55.8\%) showed more stability among the students of Relatively Advantaged Janajatis. Victims (64.86\%) encompassed the students from Disadvantaged Janajatis. Additionally, students from Dalit caste showcased the state of both bully and bullied by others $(48.44 \%)$.

The prevalence of bully, victim and bully-victim was $52.3 \%$, 58.0\% and $41.2 \%$ respectively. Verbal abuse was reported as common form of bullying. Majority of students $(65.1 \%)$ bullied others through the means of calling names and making fun of or teasing. Bullying others through the means of names or gestures with sexual meaning (39.5\%) was eminent. Physical form of bullying was found prevalent among students (Bully $18.9 \%$, Victim - 19.6\% \& Bully-victim - 9.0\%). Regardless of internet/mobile used as common form for bullying, few students $(3.8 \%)$ reported their participation in damage of property. Alarmingly, $16.2 \%$ students were suffered by damage of their property by others.

Overall bullying tendency was high in private school than in government school. Boy students from all grades $\left(8^{\text {th }}\right.$, $9^{\text {th }}$ and $10^{\text {th }}$ ) exhibited bullying characteristics in both public and private schools.

Bivariate analysis was carried out to determine the association between different factors and bullying behavior. Gender $(p=0.0001)$, school type $(p=0.039)$, depression $(p=0.0001)$ and psychosomatic symptoms burden $(p=0.0001)$ have been associated with bully characteristics. Bullying characteristics were not associated with age and school grade.

Bivariate analysis reported significant association of victim characteristics with school type $(p=0.0001)$, depression $(p=0.0001)$ and psychosomatic symptoms 
Bullying Behavior and Psychosocial Health

burden $(p=0.0001)$ regardless of gender and age.

Gender $(p=0.004)$, school type $(p=0.0001)$, depression $(p=0.0001)$ and psychosomatic symptoms burden $(p=0.0001)$ have been associated with bully-victim characteristics. No association was observed regarding age and school type with that of bully-victim characteristics.

In all cases the confidence interval was $95 \%$.

\begin{tabular}{|c|c|c|c|c|}
\hline \multirow{2}{*}{ Variables } & $\begin{array}{l}\text { Demographic } \\
\text { characteristics }\end{array}$ & \multirow{2}{*}{$\begin{array}{r}\text { Bully } \\
(\%)\end{array}$} & \multirow{2}{*}{$\begin{array}{r}\text { Victim } \\
(\%)\end{array}$} & \multirow{2}{*}{$\begin{array}{r}\text { Bully-Victim } \\
\text { (\%) }\end{array}$} \\
\hline & $\%$ & & & \\
\hline \multicolumn{5}{|l|}{ Age } \\
\hline < 14 Years $(\mathrm{n}=94)$ & 30.82 & 42.55 & 54.26 & 35.11 \\
\hline $14-15$ Years $(n=240)$ & 59.26 & 54.58 & 56.67 & 40.83 \\
\hline > 15 Years $(\mathrm{n}=71)$ & 17.53 & 57.75 & 67.61 & 50.70 \\
\hline Mean Age $($ Overall $)=14.39$ yrs & & 14.50 yrs. & $14.49 \mathrm{yrs}$. & 14.53 yrs. \\
\hline \multicolumn{5}{|l|}{ Gender } \\
\hline Females (n=209) & 51.60 & 43.06 & 53.59 & 34.45 \\
\hline Males $(n=196)$ & 48.40 & 62.24 & 62.76 & 48.47 \\
\hline \multicolumn{5}{|l|}{ Ethnicity } \\
\hline Dalit $(n=64)$ & 15.80 & 64.06 & 59.38 & 48.44 \\
\hline Disadvantaged Janajati $(\mathrm{n}=74)$ & 18.27 & 47.30 & 64.86 & 40.54 \\
\hline Religious Minorities ( $n=2$ ) & 0.49 & 0.00 & 100.00 & 0.00 \\
\hline Relatively Advantaged Janajati $(\mathrm{n}=43$ ) & 10.62 & 55.81 & 58.14 & 46.51 \\
\hline Upper Caste Group ( $\mathrm{n}=222$ ) & 54.81 & 50.45 & 54.95 & 38.74 \\
\hline
\end{tabular}

Table 2. Different forms of bullying.

Type of bullying behavior

Bullying Behavior

\begin{tabular}{|c|c|c|c|c|c|c|}
\hline \multirow[t]{2}{*}{ lype of bullyıng behavior } & \multicolumn{2}{|c|}{$(n=212)$} & \multicolumn{2}{|c|}{$(n=235)$} & \multicolumn{2}{|c|}{ ully - victim $(n=16 /)$} \\
\hline & $\mathrm{N}$ & $\%$ & $\mathrm{~N}$ & $\%$ & $\mathrm{~N}$ & $\%$ \\
\hline Verbal & 195 & 92 & 207 & 88.1 & 142 & 85.0 \\
\hline Tease & 127 & 65.1 & 147 & 71.0 & & \\
\hline Threaten & 35 & 17.9 & 30 & 14.5 & & \\
\hline Religion or caste associated Bullying & 22 & 11.3 & 27 & 13.0 & & \\
\hline Sexual meaning associated bullying & 77 & 39.5 & 82 & 39.5 & & \\
\hline $\begin{array}{l}\text { Physical (Hit, Push, Kick, Shove } \\
\text { around) }\end{array}$ & 40 & 18.9 & 46 & 19.6 & 15 & 9.0 \\
\hline Relational & 33 & 15.6 & 60 & 25.5 & 18 & 10.8 \\
\hline Direct & 13 & 39.4 & 17 & 28.3 & & \\
\hline Indirect & 25 & 75.8 & 48 & 80 & & \\
\hline Damage of property & 8 & 3.8 & 38 & 16.2 & 5 & 3.0 \\
\hline Mobile or Internet related bullying & 28 & 13.2 & 43 & 18.3 & 17 & 10.2 \\
\hline
\end{tabular}




\section{Table 3. School type and grade wise bullying tendency.}

Government

\begin{tabular}{|c|c|c|c|c|c|c|c|c|c|}
\hline \multirow[b]{2}{*}{ Grade } & \multicolumn{4}{|c|}{ Bullying Tendency } & \multirow[b]{2}{*}{ Grade } & \multicolumn{4}{|c|}{ Bullying Tendency } \\
\hline & $\begin{array}{r}\text { Neither } \\
\text { Bullied nor } \\
\text { bully }\end{array}$ & Bully & Victim & $\begin{array}{l}\text { Bully- } \\
\text { Victim }\end{array}$ & & $\begin{array}{r}\text { Neither } \\
\text { Bullied nor } \\
\text { bully }\end{array}$ & Bully & Victim & $\begin{array}{l}\text { Bully- } \\
\text { Victim }\end{array}$ \\
\hline \multicolumn{5}{|c|}{ Boys } & \multicolumn{5}{|c|}{ Boys } \\
\hline $8(n=35)$ & $34.3 \%$ & $62.9 \%$ & $54.3 \%$ & $51.4 \%$ & $\begin{array}{r}8 \\
(n=14)\end{array}$ & $14.3 \%$ & $71.4 \%$ & $78.6 \%$ & $64.3 \%$ \\
\hline $9(n=60)$ & $23.3 \%$ & $56.7 \%$ & $60.0 \%$ & $40.0 \%$ & $\begin{array}{r}9 \\
(\mathrm{n}=11)\end{array}$ & $0.0 \%$ & $54.5 \%$ & $100.0 \%$ & $54.5 \%$ \\
\hline $10(n=55)$ & $27.3 \%$ & $60.0 \%$ & $82.9 \%$ & $40.0 \%$ & $\begin{array}{r}10 \\
(n=21)\end{array}$ & $14.3 \%$ & $81.0 \%$ & $81.0 \%$ & $76.2 \%$ \\
\hline \multicolumn{5}{|c|}{ Girls } & \multicolumn{5}{|c|}{ Girls } \\
\hline $8(n=39)$ & $38.5 \%$ & $41.0 \%$ & $53.8 \%$ & $33.3 \%$ & $\begin{array}{r}8 \\
(n=12)\end{array}$ & $33.3 \%$ & $41.7 \%$ & $66.7 \%$ & $41.7 \%$ \\
\hline $9(n=89)$ & $38.2 \%$ & $44.9 \%$ & $53.9 \%$ & $37.1 \%$ & $\begin{array}{r}9 \\
(n=12)\end{array}$ & $25.0 \%$ & $58.3 \%$ & $66.7 \%$ & $50.0 \%$ \\
\hline $10(n=49)$ & $44.9 \%$ & $36.7 \%$ & $42.9 \%$ & $24.5 \%$ & $\begin{array}{r}10 \\
(n=8)\end{array}$ & $12.5 \%$ & $50.0 \%$ & $75.0 \%$ & $37.5 \%$ \\
\hline
\end{tabular}

Table 4. Bullying behaviors and its association with others.

\begin{tabular}{|c|c|c|c|c|c|c|c|c|}
\multicolumn{3}{c}{} & \multicolumn{3}{c}{ Bully } & \multicolumn{4}{c}{ Victim } & \multicolumn{3}{c}{ Bully-Victim } \\
Variables & No & Yes & P - & No & Yes & P - Value & No & Yes \\
Value & Value
\end{tabular}

Age

\begin{tabular}{|c|c|c|c|c|c|c|c|c|c|}
\hline$<14$ Years & $28.0 \%$ & $18.9 \%$ & \multirow[b]{2}{*}{0.085} & $25.3 \%$ & $21.7 \%$ & \multirow[b]{2}{*}{0.182} & $25.6 \%$ & $19.8 \%$ & \multirow{3}{*}{0.129} \\
\hline $14-15$ Years & $56.5 \%$ & $61.8 \%$ & & $61.2 \%$ & $57.9 \%$ & & $59.7 \%$ & $58.7 \%$ & \\
\hline > 15 Years & $15.5 \%$ & $19.3 \%$ & & $13.5 \%$ & $20.4 \%$ & & $14.7 \%$ & $21.6 \%$ & \\
\hline
\end{tabular}

\section{Gender}

\begin{tabular}{|c|c|c|c|c|c|c|c|c|c|}
\hline Male & $38.3 \%$ & $57.5 \%$ & \multirow{2}{*}{0.0001} & $42.9 \%$ & $52.3 \%$ & \multirow{2}{*}{0.062} & $42.4 \%$ & $56.9 \%$ & \multirow{2}{*}{0.004} \\
\hline Female & $61.7 \%$ & $42.5 \%$ & & $57.1 \%$ & $47.7 \%$ & & $57.6 \%$ & $43.1 \%$ & \\
\hline \multicolumn{10}{|c|}{ School Grade } \\
\hline 8 & $24.4 \%$ & $25.0 \%$ & \multirow{3}{*}{0.818} & $24.1 \%$ & $25.1 \%$ & \multirow{3}{*}{0.663} & $23.1 \%$ & $26.9 \%$ & \multirow{3}{*}{0.667} \\
\hline 9 & $44.0 \%$ & $41.0 \%$ & & $40.6 \%$ & $43.8 \%$ & & $43.3 \%$ & $41.3 \%$ & \\
\hline 10 & $31.6 \%$ & $34.0 \%$ & & $35.3 \%$ & $31.1 \%$ & & $33.6 \%$ & $31.7 \%$ & \\
\hline
\end{tabular}

\begin{tabular}{|c|c|c|c|c|c|c|c|c|c|}
\hline \multicolumn{10}{|l|}{ School Type } \\
\hline Public & $85.0 \%$ & $76.9 \%$ & \multirow{2}{*}{0.039} & $90.0 \%$ & $74.0 \%$ & 0,0001 & $86.1 \%$ & $73.1 \%$ & \multirow{2}{*}{0.0001} \\
\hline Private & $15.0 \%$ & $23.1 \%$ & & $10.0 \%$ & $26.0 \%$ & & $13.9 \%$ & $26.9 \%$ & \\
\hline \multicolumn{10}{|l|}{ Depression } \\
\hline Yes & $40.9 \%$ & $67.9 \%$ & \multirow{2}{*}{0.0001} & $34.7 \%$ & $69.8 \%$ & \multirow{2}{*}{0.0001} & $42.9 \%$ & $72.5 \%$ & \multirow{2}{*}{0.0001} \\
\hline No & $59.1 \%$ & $32.1 \%$ & & $65.3 \%$ & $30.2 \%$ & & $57.1 \%$ & $27.5 \%$ & \\
\hline \multicolumn{10}{|c|}{ Psychosomatic symptoms Burden } \\
\hline None & $69.4 \%$ & $52.8 \%$ & \multirow{3}{*}{0.0001} & $80.6 \%$ & $46.4 \%$ & \multirow{3}{*}{0.0001} & $71.4 \%$ & $45.5 \%$ & \multirow{3}{*}{0.0001} \\
\hline Medium & $16.1 \%$ & $26.9 \%$ & & $12.4 \%$ & $28.5 \%$ & & $15.1 \%$ & $31.1 \%$ & \\
\hline High & $14.5 \%$ & $20.3 \%$ & & $7.1 \%$ & $25.1 \%$ & & $13.4 \%$ & $23.4 \%$ & \\
\hline
\end{tabular}




\section{DISCUSSION}

Our study revealed the overall prevalence of bullying behavior (either bully or victim) as $69.14 \%$. Finding was inconsistent with a study conducted in India. ${ }^{1,2,13}$ Observational and analytical study conducted in India noted higher prevalence of bullying as $60.4 \% .{ }^{1}$ Similarly, in a study in North Indian City, prevalence of bullying behavior was $53 \%$. However, the result was inconsistent with the studies conducted in western countries. ${ }^{2-5,9,14,15}$ $22 \%$ of sample was classified as involved in bullying as reported by study in Los Angeles. ${ }^{16}$ Similarly, a study in United States noted $29.9 \%$ of sample involved in moderate or frequent bullying. ${ }^{14}$ Verbal bullying was the most common form of bullying reported by our study. Finding was in agreement with the various researches conducted. ${ }^{1-5,9}, 14,15$

Many studies have noted the bullying behavior was more prominent among boys as compared to girls., 12, 13, 16 Our study showed the similar findings. In contrast to the study carried out in India ${ }^{2}$ prevalence of bullying among boys was $63.9 \%$ as compared to girls which was $53 \%{ }^{1}$ Males students were significantly engaged in aggressive behavior compared to female students. ${ }^{13}$ A cross sectional comparative study of 40 countries suggests the higher estimates of bullying for boys from $8.6 \%$ to $45.2 \%$ and among girls rates ranged from 4.8 to $35.8 \% .{ }^{17}$ In our study, majority of the victims were bullied by their classmates. Perpetrators of bullying on victims mainly was done by more than one students and is consistent with the study carried out in Iran. ${ }^{15}$

Consistent with the extensive literature on bullying, findings from this investigation offer further evidence on male students engaged in aggressive behavior more than female student. Boys have more freedom to express their freedom and they tend to be ready to do anything for sake of maintaining their place in group. In different ways, they victimize others. On the other hand, girls are usually taught to avoid direct and aggressive behavior in different ways. ${ }^{12}$

Our study revealed the statistically significant association between bullying behavior, psychological and psychosomatic health. Psychosomatic score was comparatively higher among victim and bully-victim. Depression was noted higher among them. These results are consistent with various study related to school bullying. ${ }^{18-20}$ Researchers contemplate the feeling of guilt or shame may be influential factor for depression behind bullying. ${ }^{21}$ Anti-bullying programs involving boys and girls in a different ways are highly recommended to be conducted. ${ }^{22}$ As showed by extensive research, bullying and victimization are in the increasing trend. ${ }^{23}$

\section{CONCLUSIONS}

Bullying among school children is the prominent issue suggested by various studies and literatures. Being bullied is further associated with increased risk of developing long-lasting harm. However, limited body of research related to bullying has been conducted in Nepal. This research provides the insight towards emerging issue and consequences of bullying among school children. It is pivotal to investigate and conduct further research in order to demonstrate the deleterious effects of bullying in mental health of school children. Current findings of the study suggest variable prevalence of bullying in types of school and sex of students. Public and private specific and gender specific intervention program is recommended.

This study provides insights into the bullying tendency among school students in Nepal. Furthermore, this study made possible to compare the bullying prevalence among public and private school. Though the data were collected through self - administered method, to minimize the subjectivity, students were provided with a detailed definition of bullying along with examples. Additional strength of this study is that it provides information on psychosocial correlates of bullying among school students. Although the study area was selected purposively, random sampling method was used to select the study population and study unit. Pre-testing of the tools add another strength in this study.

At the same time study should be considered in light of several important limitations. The study area has been chosen purposively and the sample size is relatively small. So, this study cannot be generalized in larger population. Since, the study mainly focused at obtaining the information on prevalence of different forms of bullying behavior, more in - depth information, such as might be acquired from intervention study addressing the bullying are not available. The data are cross-sectional, and as such, the direction of relationship among the variables cannot be determined. Another limitation is that we had to reliance on the self-administered method of data collection, which might be sometime impotent to gain the reliable information. Because individual perception on bullying may vary.

\section{REFERENCES}

1. Forero R1 ML, Rissel C, Bauman A. Bullying behaviour and psychosocial health among school students in New South Wales, Australia: cross sectional survey. BMJ. 1999;319(7206):344-8. [Full Text]

2. Ramya SG1 KM. Bullying among school children: prevalence and association with common symptoms in 
childhood. Indian J Pediatr. 2011;78(3):307-10. [PubMed]

3. Malhi P1 BB, Sidhu M. Aggression in schools: psychosocial outcomes of bullying among Indian adolescents. Indian J Pediatr. 2014;81(11):1171-6.[PubMed]

4. Boulton MJ1 UK. Bully/victim problems among middle school children. Br J Educ Psychol. 1992;62(Pt 1):73-87. [Link]

5. Juvonen J1 GS, Schuster MA. Bullying among young adolescents: the strong, the weak, and the troubled. Pediatrics. 2003;112(6 Pt 1):1231-7. [PubMed]

6. Williams K1 CM, Logan S, Robinson D. Association of common health symptoms with bullying in primary school children. BMJ. 1996;313(7048):17-9.[PubMed]

7. Lucia S. Correlates of bullying in Switzerland. Eur J Criminol. 2016;13(I):50-66. [Full Text]

8. Mehta M. PVM. Bullying in Indian School Going Adolescents. Indian J Pediatr. 2014;81(11):1143-4.[Full Text]

9. Kaltiala-Heino R1 RM, Marttunen M, RimpeläA, Rantanen P. Bullying, depression, and suicidal ideation in Finnish adolescents: school survey. BMJ. 1999;319(7206):348-51. [Full Text]

10. Sonia S, Joaquim C, Gustave NF. Bullies, victims and bullyvivtimd impact on health profile. Educação, Sociedade \& Culturas. 2013;38:53-75.[Full Text]

11. Hazelden Foundation. The Olweus Bullying Prevention Program Frequently Asked Questions. 2007. Available from: hazelden.org/olweus

12. Rana N. School Bullying: Introducing the Issue. Journal of Education and Research. 2008;1(1):62-8. [Full Text]

13. Limber DOaS. Bullying Prevention Program. EIliott DS, editor. Chicago: Venture Publishing, Golden. Colorado and C 8 M Press, Denver, Colorado; 1999.[Full Text]

14. Nansel TR OM, Pilla RS, Ruan WJ, Simons-Morton B, Scheidt P. Bullying behaviors among US youth: prevalence and association with psychosocial adjustment. JAMA. 2001;285(16):2094-100. [Full Text]
15. Soori H, Rezapour M, Khodakarim S. Epidemiological Pattern of Bullying among School Children in Mazandaran Province-Iran. J Child Adolesc Behav. 2014;2(145):2. [Full Text]

16. Gladden RM, Vivolo-Kantor, A.M., Hamburger, M.E., \& Lumpkin, C.D. Bullying Surveillance Among Youths: Uniform Definitions for Public Health and Recommended Data Elements, Version 1.0. In: Education USDo, editor. Atlanta, GA: National Center for Injury Prevention and Control,Centers for Disease Control and Prevention 2014. [Full Text]

17. Craig W, H-FY, Fogel-Grinvald H, Dostaler S, Hetland J, Simons-Morton B, et al. HBSC violence and injuries prevention focus group; HBSC bullying writing group. a cross-national profile of bullying and victimization among adolescents in 40 countries. Int J Public Health. 2009;54(2):216-24.[PubMed]

18. Roland E. Bullying, depressive symptoms and suicidal thoughts. Educational Research. 2002;44(1):55-67.[Full Text]

19. Yang SJ KJ, Kim SW, Shin IS, Yoon JS. Bullying and victimization behaviors in boys and girls at South Korean primary schools. J Am Acad Child Adolesc Psychiatry. 2006;45(1):69-77.[PubMed]

20. AC B. The impact of direct and indirect bullying on the mental and physical health of Italian youngsters. Aggressive Behavior. 2004;30(5):343-55. [Link]

21. Rigby K. Consequences of bullying in schools. Can J Psychiatry. 2003;48(9):583-90.[PubMed]

22. R TA. Sugar and spice and puppy dogs' tails: the psychodynamics of bullying. J Am Acad Psychoanal Dyn Psychiatry. 2007;35(2):243-58.[PubMed]

23. Wilson ML1 BP, Viswanathan B, Suris JC. Bullying among adolescents in a sub-Saharan middle-income setting. J Adolesc Health. 2012;51(1):96-8. [PubMed] 